\title{
Group meetings after critical illness-Giving and receiving strength
}

Carl G. Backman, Mona Ahlberg, Christina J ones and Gunilla Hollman Frisman

The self-archived postprint version of this journal article is available at Linköping University Institutional Repository (DiVA):

http:// urn.kb.se/ resolve?urn=urn:nbn:se:liu:diva-149725

N.B.: When citing this work, cite the original publication.

Backman, C. G., Ahlberg, M., J ones, C., Hollman Frisman, G., (2018), Group meetings after critical illness-Giving and receiving strength, Intensive \& Critical Care Nursing, 46, 86-91.

https:// doi.org/ 10.1016/j.iccn.2017.11.003

Original publication available at:

https:// doi.org/ 10.1016/j.iccn.2017.11.003

Copyright: Elsevier (12 months)

http:// www.elsevier.com/

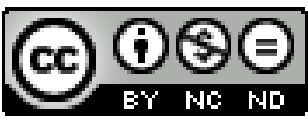




\section{Group-meetings after critical illness - giving and receiving strength}

Carl G Bäckman CCRN, PhD ${ }^{1}$, Mona Ahlberg CCRN, MSc ${ }^{1}$, Christina Jones CCRN, $\mathrm{PhD}^{2}$, Gunilla Hollman Frisman, CCRN, Ass. Professor ${ }^{3}$.

${ }^{1}$ Department of Anesthesiology and Intensive Care, Vrinnevi Hospital Norrköping, Sweden.

${ }^{2}$ Musculoskeletal Biology, Institute of Ageing \& Chronic Disease, University of Liverpool, Liverpool, UK.

${ }^{3}$ Department and Anaesthetics, Operations and Speciality Surgery Center and Department of Medical and Health Sciences, Linköping University, Linköping, Sweden.

Conflict of interest

There is no conflict of interest

Acknowledgements

We are grateful to the participating patients for sharing their experiences of group meetings. The study was supported by grants from Department and Anaesthetics, Operations and Speciality Surgery Center, Region Östergötland, Sweden.

Corresponding author: Carl Bäckman, Department of Anesthesiology and Intensive Care, Vrinnevi Hospital, 60182 Norrköping, Sweden, E-mail;

carl.backman@regionostergotland.se Phone +46101042337 
Abstract

Introduction: An increasing number of intensive care patients are surviving critical illness, but many develop mental, cognitive and physical impairments after discharge. Adapting to a new life situation, often with major challenges, implies the need of support. Therefore, it is important to develop interventions aimed at promoting recovery.

Objective: The aim was to describe former intensive care patients' feelings of sharing their experience of critical illness with other former patients.

Method: Former intensive care patients $(n=17)$ participated in group meetings and wrote about their thoughts in a notebook after each group meeting. To deepen the understanding of the former patients' experience 11 of the former patients were interviewed. The notes in the notebooks and the interviews were analyzed using qualitative content analysis.

Findings: Meeting others revealed to the former patients new dimensions of being critically ill, and they both gave and received strength from each other. The meetings were meaningful as they gained insight into other patients' lives, and realized what it meant to survive intensive care.

Conclusions: The group meetings meant sharing experiences and understanding the process of survival after critical illness. Giving and receiving strength from others helped the participants to go further.

Keywords: Content analysis, Critical care nursing, Critical illness, Group meetings, Intensive care rehabilitation.

\section{Implications for clinical practice}

- Group meetings help former intensive care patients to understand what it means to survive intensive care.

- Sharing experiences with others is one way to both give and receive strength.

- Individuals felt aided in their battle to recover by the reactions of the other patients 


\section{Introduction}

After experiencing life-threatening illness or injury requiring a stay at an intensive care unit (ICU), life often changes dramatically during and after the period of illness. Health-related quality of life (HRQoL) is reported to be significantly lower for patients after critical illness compared with the general population (Davidson et al., 1999; Orwelius et al., 2005; Oeven et al., 2010). Many patients do not return to the same physical status as before their critical illness, which means that they need to adapt to a new life situation, often with major challenges. During the first year of convalescence, patients struggle for independence with their efforts focused on three domains; recovering physical strength, regaining functional capacity and resuming domestic roles (Ågård et al., 2012).

Furthermore, a substantial proportion of survivors experience cognitive impairment affecting memory and attention function (Desai et al., 2011). The fragmentary nature of memories from the patients' stay in the ICU and the delusional memories, such as hallucinations and nightmares, make it difficult for them to understand what really happened. (Jones et al., 2000; Jones et al., 2007; Jones et al., 2010; Wade et al., 2015). Critical illness thus affects long-term health and well-being, and consequently it is important to develop interventions aimed at improving well-being, even after the patient has left the ICU (Angus and Carlet, 2002, Jensen et al., 2015). One form of intervention is writing diaries in order to fill memory gaps, and this has been well received by patients and their relatives (Bäckman and Walther, 2001; Engström et al., 2009; Bäckman et al., 2010; Egerod and Bagger, 2010; Jones et al., 2010; Jones et al., 2012; Garrouste-Orgeas et al., 2012), although Ullman et al. (2015) in their review suggest that clear evidence of the psychological effects of diaries still is limited. 
Further interventions are ICU follow-up clinics, where former ICU-patients have a chance to discuss their ICU stay, and to be screened for complications and referred to specialist services, where necessary (Egerod et al., 2013). Organised by Milton Keynes Hospital, UK, meetings for former ICU patients and their relatives have been ongoing since 2005 (Peskett and Gibb, 2009). The ICU follow-up team and former patient and family volunteers hold drop-in sessions where recent patients and their relatives can meet and talk. In this report the participants of these meetings experienced them as giving positive support.

Follow-up clinics and drop-in sessions are often used to evaluate the patients' progress (Egerod et al., 2013). Former patients may attend with the intention of meeting each other and discussing their experience of being critically ill and consequently not further burdening their relatives. Thus, the aim of this study was to describe former intensive care patients' feelings of sharing their experiences of critical illness and recovery period with other former patients.

\section{Method}

As there is limited knowledge about former patients' feelings of sharing their experiences of critical illness with other former patients, a qualitative inductive descriptive design was chosen. A qualitative approach aims to deepen and broaden the knowledge about former patients' thoughts about sharing their experience of critical illness during group meetings (Krippendorf, 2013). 


\section{Participant}

The Ethical board approved using data from the ICU follow-up clinic to get in contact with former ICU patients. The first author, working as an ICU nurse at the ICU ward and at the ICU follow-up clinic, did the data selection out of patients that had visited the ICU follow-up clinic. All patients who had been treated in a general ICU at a regional Hospital, in the previous 3-18 months were invited to participate if they met the following inclusion criteria: Adults over 18 years old, an ICU stay more than 96 hours had visited the follow-up clinic at least one time, able to attend both group meetings, ability to speak and write in Swedish. Twenty five former patients reached the inclusion criteria and were invited to participate of whom seventeen agreed to participate in the study. Those who declined participation claimed that they were busy and couldn't attend to both meetings or had problem with hearing during group sessions.

\section{Intervention}

The former ICU patients participated in two group meetings, one month apart, with three to six patients in each group. An experienced ICU nurse (the first author) facilitated the group discussion and made sure that everyone was given time to speak and that the participants kept to the topic. At the first session all the patients talked about why they had been admitted to the ICU and their experiences of their stay until discharge to a general ward. They discussed what they could remember and what they had been told by relatives or read in their ICU diary. Subsequently, time was allocated for the other patients to ask questions. During the second meeting, the focus of the discussion was on the experience of leaving the ICU, the time on the general ward, and the recovery at home. 


\section{Data collection}

An invitation to participate in group meetings was sent by mail and the patients were then contacted by phone. The postal invitation included information about the study, the group meetings and the confidential and voluntary nature of the study. An informed consent form was provided to sign and send back.

Four group meetings were held, with three to six former ICU patients in each, for a duration of two hours on two occasions at monthly intervals. The first meeting opened with an introduction of the participants themselves. The topic of this meeting was the critical illness and their experience of the ICU care. The second meeting dealt with the recovery period after ICU care until this meeting. Thereafter, the group discussed freely. To protect everyone's privacy it was emphasized that what was discussed in the meeting should not be shared outside the group.

After each session, the participants wrote down their feelings in a notebook that they were given at the first meeting. According to Polit and Beck, (2008), notebooks are used to collect data related to specific aspects of experiences. These questions were posed to guide the patients' comments in the notebooks:

- Do you feel that you have been affected in some way by the meeting? If so, how ? Why?

- Has it brought up feelings for you? Which? Why?

- Did today’s meeting give you something? If so, what?

All participants sent their notebooks back within 14 days of the meeting. As the content of the notebooks was sparse, all participants were asked to consent to an interview in order to deepen the understanding of the meaning of the group meeting. 
Two to three months later, a semi-structured interview was conducted to obtain further insight. Eleven of the 17 former patients who participated in the group meetings, seven men and four women, gave their informed consent to be interviewed. All interviews were taperecorded and performed at the hospital in a room next to the ICU, except one which was performed in the patient's home. The questions from the notebook were used to guide the interviews and the interviews lasted between 30-60 minutes. All interviews were conducted by the first author, who also transcribed the interviews verbatim.

\section{Data analysis}

Qualitative inductive content analysis was used to deepen and broaden the insight and understanding of former patients' feelings of sharing their experiences of critical illness with other former patients. This was done by analyzing the contents of the comments in the notebooks and the transcribed interviews (Krippendorff, 2004; Krippendorff, 2013). The text was read several times by the first, second and the last authors, and meaningful units, relevant to the purpose of the study, were identified individually. Similar meaningful units were then given the same code and sorted into subcategories and categories. To ensure credibility, all the authors discussed similarities and differences during the analysis until consensus was reached. The meaningful units, subcategories and categories were read over and over again and the analysis steps were processed back and forth to validate identified codes. Verbatim quotes have been used in this paper to give the reader an opportunity to evaluate the conformance between the interviews and the categories. This increases the credibility of the findings (Krippendorff, 2013; Patton, 2002). 
To ensure dependability and to verify that the findings were understood and interpreted correctly, a third session was organized when eleven participants from the first two group meetings were presented with a summary of the data analyzed from the notebooks. The participants verified that the findings had been correctly understood and interpreted (Lincoln and Guba, 1985). Together, these techniques support the trustworthiness of this qualitative study.

\section{Ethical considerations}

The study was approved by the Regional Ethical Committee in 2012, and an additional request to undertake interviews was approved in 2014. Because of the former patients' possible distress when discussing their experience of being critically ill with other former patients, a welfare officer employed at the ICU was available the day of the meeting and whenever needed.

\section{Findings}

Former ICU patients ( $\mathrm{n}=17)$, five of whom were women participated (Table 1).

The patients had been admitted to the ICU because of life-threatening illness caused by postoperative complications, trauma, sepsis, Guillain-Barré syndrome or pneumonia and had stayed in the ICU between five and 47 days. The time from the former patients' date of discharge from the ICU to the date on which the meetings were held ranged from 94 to 600 days. None of the participants had ever met another ICU patient.

The qualitative content analysis of the comments in the notebooks and the interviews generated four categories: Meaningful discussions, Understanding the meaning of surviving 
intensive care, Giving and receiving strength, and The Nature and structure of group meetings. There were also six subcategories (Table 2). The quotes presented are excerpts from the notebooks (N) and from the interviews (I).

Meaningful discussions

\section{Getting insight}

Some participants said that they had been doubtful before attending the meetings, but found that participating in the group meetings fulfilled their needs.

One might be doubtful before, but once there, the meetings fulfill needs you were not aware of. (N/6)

They recommended attending such meetings to others in a similar situation. The meetings gave the participants an insight and a wider perspective of life. After meeting and listening to other former patients, they understood and interpreted the meaningfulness of the discussions.

Afterwards I felt that the meeting became awkward since one of the participants had suffered so much more than we others had. Then I pointed out how important it was to meet others to accept and be able to go on. (I/6)

The meeting was more sensitive than expected as there were participants with different illnesses/traumas that meant different recovery possibilities, and some had thought about what was said during the meeting after coming home. They had a sense that they had gained a 
deepened life experience. Many participants felt that they gave much more information about themselves during the meeting than they had anticipated.

We were a closed group and it felt as though we opened ourselves up to the others. It was hard to hear the others' stories but that gave us a lot. It was thanks to the group members being so engaged in others' experiences and the feeling of a sense of security in how the group meetings were led. (I/8)

Through the group meetings, many thoughts about their period of critical illness came up that they had forgotten, and they felt that these were clarified by discussion with the other participants.

Of course I had been severely injured in my accident, but I gained a new sense of perspective through meeting others. I was amazed when I realized that I had become stronger after these meetings, and that it's OK that my life and injuries appear as they do. (I/5)

It was felt that the meetings contributed to an insight and acceptance of the changed life situation, although it was hard to reach this acceptance.

\section{Shared experiences}

Meeting people with similar experiences and sharing this was different from talking to others who had no experience of being critically ill. The view was expressed that it felt really good to meet in this group and share experiences.

It was a good set-up, I met like-minded people. (N/16) 
This shared experience facilitated the understanding of being critically ill even though the participants in the group had different diagnoses and caring needs.

Everyone in this group had another understanding of each other even though they had suffered a different illness. It's difficult for someone who hasn't experienced what it's like being a patient on the ICU to put themselves in this situation. (I/11)

During the second meeting, when the group members had got to know each other more, they felt more comfortable to talk. Strong feelings were experienced when sharing thoughts about their lives after the ICU stay and the discharge from the hospital.

At the second meeting, I was deeply moved when the others told us how their life was today. One of the participants in particular had a great need of assistance in daily life. (I/7)

Some of the participants now had a disability that had obviously changed their life, and they had to assess their entire future in the light of this new situation.

Understanding the meaning of surviving intensive care

\section{Confirmation}

Meeting other patients was a reminder of being through something significant (the ICU stay), after the meetings some participants said that they had a sense of being healthier than before. 
It became clear to me that I was not alone, we were all suffering in one way or another, and I was not the one hardest hit. (N/4)

The feeling of confirmation was related to not previously knowing how others experience critical illness but now having the possibility to meet and talk to others having similar experience of critical illness and ICU care.

\section{Relief}

Prior to the group meetings the participants had tried to continue to live their lives as before the critical illness. Participating in the group meetings contributed to an insight and consciousness of the fact that they had been critically ill; consequently they could allow themselves to reduce the demands on themselves.

I have reduced the demands I put on myself, and realize that I can accept help and demand that others show consideration - I have become mentally stronger. (I/3)

There was a sense of becoming mentally stronger from suffering and surviving the critical illness. When listening to the others' stories and their experiences of the period of critical illness a sense of devoted thankfulness and humility in life was experienced.

Giving and receiving strength

Hope

A slow recovery was hard to accept as the participants had expected life to return to normal when discharged from hospital and going back home again. 
I was upset that I had not recovered quicker, but the others told me how long it had taken them and that gave me hope. (N/4)

Listening to the others recounting their experiences of the recovery gave a sense of hope, especially when one participant reported that he had, at one moment during their ICU care, taken a decision to do everything to survive, but that earlier during that same stay he had thoughts about giving up on life.

I have realized how frail and little we are, but have also understood the enormous powers that exist in each and every one of us, and that there is a glow of eagerness and energy to live. $(N / 2)$

\section{Going further}

Some of the participants spoke about gaining strength from the meetings when meeting older patients with their spark of life.

I felt I gained power and energy from these meetings, I got a boost of energy from seeing the life force these elderly men had, and the feeling was mutual. (N/11)

Telling one's story and talking to the others in the group facilitated talking to family members and one participant felt that it now was easier to talk to his wife about what he was worried or sad about. 
Having attended these meetings I have become more open for conversation with my partner on why I am sad and what it is that worries me. I couldn't do that before and now things function perfectly. (I/9)

Everyone in the group seemed positive about their future and their lives, although some had to live with a disability.

The Nature and structure of group meetings

The participants all said that it was easy to talk to the other former patients and that if they just talked to the staff they didn't get a sense of how others in a similar situation felt about being critically ill.

If you only meet personnel, then you don't know how others have experienced things - this group was important for me. (N/11)

The participants felt that the nurse coordinating the meetings had an important role during the first meeting, although one patient said it would be possible to run such meetings without a nurse in the future. Furthermore, the participants reported that the first meeting, which started with an individual telling their own story about their memories of their time on the ICU, as well as the second meeting, when someone spoke about the time after discharge, was good starting points for the discussions, even though no one had been prepared before to tell their story. 
I wasn't prepared to tell "my story" about why I came to the ICU. No one else was either but that was not a disadvantage; if I had prepared myself for this I would only have been nervous. $(N / 9)$

Although some participants did not remember anything about their ICU stay, they told the others about what they had been told by relatives, at the follow-up clinic or what they had read in their ICU diary.

When the participants started to speak, everyone listened and was interested. Some told the others about the awful dreams they had experienced, some spoke about how hard it was to sleep in the ICU, and afterwards the others could agree and add their thoughts or ask questions. Some groups really inspired each other to speak about things they had not spoken about to anyone else. Everyone listened to the person who spoke with great respect. The atmosphere during the group meetings was experienced as very positive.

The meetings were highly valued even though the participants did not have similar experiences about their critical illness, treatment and recovery. The time that had passed since being in critical care, six months after discharge, meeting at least twice, and having a group of five former patients were seen as optimal conditions to promote a deep discussion.

No more than five, partly because you don't hear so well with age, and partly because if you're going to discuss at depth, as we did, then there shouldn't be more. (N/1)

Having a mix of genders in the groups was appreciated, but a woman found it a little difficult to be the only female in a group, feeling that men and women may experience critical illness and critical care differently. 
I was the only woman in my group; it would have been nicer if there were others since I believe that men and women experience situations in different ways. (N/17)

\section{Discussion}

This is to our knowledge the first research study describing former intensive care patients' feelings of sharing their experiences of critical illness and recovery period with other former patients in nurse-led group meetings after critical illness and ICU care. The main finding was that the participants felt that they had meaningful discussions and were strengthened.

The meetings gave the participants a great insight into others' experiences. They felt that the meetings provided meaningful discussions, and a better understanding of what it means to survive intensive care and deal with physical and mental problems. This was confirmed among other former ICU patients who described that life had a different meaning either through being thankful for surviving and still living, or struggling with negative feelings and not being able to go back to ordinary life (Abdalrahim et al.,2014; Pattison et al.,2015). The participants in our study said that since they had become ill and needed support from the ICU, they had been on a journey and that finally, after the group meetings, they understood what it means to survive intensive care. They felt confirmed by sharing others' experiences. Confirmation has also been described by Engström et al. (2007), who report that being understood and confirmed by close relatives gave critically ill patients the power to continue to struggle and be motivated to stay alive.

Like former patients in our study the participants in the ICU-steps support group in Milton Keynes Hospital UK, felt that they benefitted from sharing experiences with others (Peskett 
and Gibb, 2009). However, since the meetings organised by Milton Keynes Hospital were arranged for former patients and their relatives, the findings of the current study are not fully comparable as the intervention was aimed only at former patients, with the intention of helping them to exchange their experiences of critical illness.

Some of the participants experienced the positive feeling that they could both give and receive strength from meeting others. If others could live with problems worse than you perceive yours to be and still not give up, then it kept you motivated to go on with your rehabilitation. This finding is supported by former ICU patients who felt that they got stronger from meeting others (Peskett and Gibb, 2009). Similarly, critically ill people gained motivation to continue to struggle for life through close relatives being present during their ICU stay (Engström et al., 2007). Also, thinking about the world outside the hospital motivated them to strive for a future life (Wåhlin et al., 2009). Just telling one’s story to interested people who were able to understand also gave a sense of own insight and hope for the future (Ewens et al., 2014). Consciousness about surviving a critical illness has been shown to encourage strategies such as active coping, positive reframing, optimism, humor, acceptance and trying to continue leisure time activities (Chahraoui et al., 2015).

Furthermore, partners who have participated in group meetings also benefitted from meeting others with similar experiences; they felt togetherness in being partners of a critically ill person needing ICU care. The partners felt that sharing existential thoughts strengthened them and facilitated insight into their own experience and life situation, but some of them said that they would have benefitted more from these meetings, if they had been offered earlier in the trajectory, especially if it was more than a year since their partner were an ICU-patient. (Ahlberg et al., 2015). 
Interestingly, new models aimed at supporting ICU patients' and caregivers' recovery have been tested, with positive results. Kahn et al. (2015) used an interdisciplinary care model, consisting of a registered nurse, a critical care physician, a social worker, a medical assistant and a psychometrician, for ICU survivors emanating from a patient-centered care philosophy with a mission to maximize cognitive, physical, and psychological recovery.

All of the study participants recommended offering these meetings at least twice as they felt that group meetings with former ICU patients gave a deeper understanding of their critical illness and recovery period compared to visiting the ordinary ICU follow-up clinic with a conversation with a healthcare professional. Probably some former patients would find one follow-up meeting enough, but the experience from this study suggests that most former patients would want more follow-up meetings.

We believe that visiting the follow-up clinic is a prerequisite for a deeper group discussion with other former ICU patients. The present shortage of ICU nurses means that it can be difficult for an ICU to use resources for ICU follow-up clinics and consequently also to offer group meetings for former ICU patients. One possibility could be to implement the ICU follow-up strategy, ICUsteps support groups, as described by Peskett and Gibb (2009) where former patients and relatives volunteer to arranged "open drop in meetings" where former ICU patients and their relatives can meet and talk (Peskett and Gibb, 2009).

The groups were planned to have a mix of genders; however, one female complained that it was difficult being the only female member. It was unfortunate that one group only consisted of one female and three men as one women canceled her participation on the day for the meeting. The lone female expressed the feeling that women and men may have different 
experiences of being critical ill and she may have felt more supported with another woman in the group.

The participants said that six months after ICU would be the optimal time for group meetings. This is in accordance with the review by Jensen et al. (2015) reporting that follow-up after ICU care might have positive effects 3-6 months after discharge.

Limitations

The use of two different data collection methods could be criticized. As notebooks are recommended as a data collection tool related to specific aspects of experiences (Polit and Beck, 2008) notebooks were used to collect the immediate experience of the group meetings. But as the content written in the notebooks was more limited than expected, the participants were asked to consent to an interview in order to deepen the understanding of the meaning of the group meetings. However, analyzing both the comments in the notebooks and the individual interviews gave a broad perspective and a deeper insight into the value of group meetings to former ICU patients.

The qualitative method does not allow any analysis of drop-outs, so we do not know anything about former patients that did not participate. However former patients' who declined participation surely could have contributed with expanded experiences.

Another limitation with inviting potentially vulnerable former ICU patients to discuss their experience of being critically ill with unfamiliar people is that they gave much more information about themselves than they had anticipated, which could be seen as unethical. 
However, the former patients gave written informed consent before taking part in the meetings. They were thoroughly informed that they were expected to tell their story to the group, although no one was forced to talk about any experiences outside their comfort zone. Former patients were also informed that anything discussed within the group was confidential and should remain within the group. Still, it is not a guarantee that their stories remained in the group.

\section{Conclusion}

The advantage of group meetings was the sharing of meaningful discussions between former ICU patients who were able to understand each other. Giving and receiving strength and being confirmed helped the participants to go further in life. The clinical implication for future interventions means offering group meetings for former ICU patients approximately six months after ICU care.

\section{Implications for clinical practice}

- Group meetings help former intensive care patients to understand what it means to survive intensive care.

- Sharing experiences with others is one way to both give and receive strength.

- Individuals felt aided in their battle to recover by the reactions of the other patients. 


\section{References}

Abdalrahim, M.S., Zeilani, R.S. 2014. Jordanian survivors' experiences of recovery from critical illness: a qualitative study. Int. Nurs. Rev. 61(4), 570-577.

Ågård, A.S., Egerod, I., Tonneson, E., Lomborg, K. 2012. Struggling for independence: A grounded theory study on convalescence of ICU survivors 12 months post ICU discharge. Intensive Crit. Care Nurs. 28, 105-113.

Ahlberg M, Bäckman C, Jones C, Walther S, Hollman Frisman G. 2015. Moving on in life after intensive care - partners' experience of group communication. Nurs. Crit. Care. 20(5), 256-63.

Angus, D.C., Carlet, J., 2002. Surviving intensive care. Update in intensive care and emergency medicine, no 39. Springer, Berlin.

Bäckman, C.G., Walther, S.M. 2001. Use of a personal diary written on the ICU during critical illness. Int. Care Med. 27(2), 426-429.

Bäckman, C.G., Orwelius, L., Sjöberg, F., Fredrikson, M., Walther, S.M. 2010. Long-term effect of the ICU-diary concept on quality of life after critical illness. Acta Anaesth. Scand. 54(6), 736-43.

Chahraoui, K., Laurent, A., Bioy, A., Quenot, J.P. 2015. Psychological experience of patients 3 months after a stay in the intensive care unit: A descriptive and qualitative study. J. Crit. Care. 30(3), 599-605. 
Davidson,T.A., Caldwell, E.S., Curtis, J.R., Hudson, L.D., Steinberg, K.P. 1999. Reduced quality of life in survivors of acute respiratory distress syndrome compared with critically ill control patients. JAMA. 281, 354-360.

Desai, S.V., Law, T.J., Needham, D.M. 2011. Long-term complications of critical care. Crit. Care Med. 39(2), 371-379.

Egerod, I., Bagger, C. 2010. Patients' experiences of intensive care diaries - a focus group study. Intensive Crit. Care Nurs. 26(5), 278-87.

Egerod, I., Risom, S.S., Thomsen, T., Storli, S.L., Eskerud, R.S., Holme, A.N., Samuelsson, K.A. 2013. ICU-recovery in Scandinavia: a comparative study of intensive care follow-up in Denmark, Norway and Sweden. Intensive Crit. Care Nurs. 29(2),103-111.

Engström, Å., Söderberg, S. 2007. Receiving power through confirmation: the meaning of close relatives for people who have been critically ill. J. Adv. Nurs. 59(6), 569-576.

Engström, Å., Grip, K., Hamren, M. 2009. 'Experiences of intensive care unit diaries: touching a tender wound'. Nurs. Crit. Care. 14, 61-67.

Ewens, B., Chapman, B., Tulloch, A., Hendricks, J.M. 2014. ICU survivors' utilization of diaries post discharge: A qualitative descriptive study. Aust. Crit. Care. 27(1), 28-35. 
Garrouste-Orgeas, M., Coquet, I., Perie,r A., Timsit, J.F., Pochard, F., Lancrin, F., Philippart, F., Vesin, A., Bruel, C., Blel, Y., Angeli, S., Cousin, N., Carlet, J., Misset, B. 2012. Impact of an intensive care unit diary on psychological distress in patients and relatives. Crit. Care Med. 40(7), 2033-2040.

Jensen, J.F., Thomsen, T., Overgaard, D., Bestle, M.H., Christensen, D., Egerod, I. 2015. Impact of follow-up consultations for ICU survivors on post-ICU syndrome: a systematic review and meta-analysis. Intensive Care Med. 41(5), 763-765.

Jones, C., Griffiths, R.D., Humphries, G.H. 2000. Disturbed memory and amnesia related to intensive care. Memory; 8(2), 79-94.

Jones, C., Backman, C., Capuzzo, M., Flaatten, H., Rylander, C., Griffiths, R.D. 2007. Precipitants of post-traumatic stress disorder following intensive care: a hypothesis generating study of diversity in care. Intensive Care Med. 33(6), 978-985.

Jones, C., Bäckman, C., Capuzzo, M., Egerod, I., Flaatten, H., Granja, C., Rylander, C., Griffiths, R.D. and RACHEL group. 2010. Intensive care diaries reduce new onset PTSD following critical illness: a randomized, controlled trial. Crit. Care. 14:R168.

Jones, C., Bäckman, C., Griffith, R.D. 2012. Intensive care diaries reduce PTSD-related symptoms in relatives following critical illness. Am. J. Crit. Care. 21(3), 172-176.

Khan, B., Lasiter, S., Boustani, M. 2015. Critical care recovery center: An innovative collaborative care model for ICU survivors. Am. J. Nurs. 115(3), 24-31. 
Krippendorff, K. 2004. Reliability in content analysis: Some common misconceptions and recommendations. Hum. Commun. Res. 30(3), 411-433.

Krippendroff, K. 2013. Content Analysis: An Introduction to Its Methodology, third ed. SAGE Publications Inc., Thousand Oaks California.

Lincoln, Y., Guba, E. 1985. Naturalistic Inquiry, SAGE Publications Inc., Newbury Park, CA.

Oeven, S.G,, Vandijck, D.M., Benoit, D.D., Annemans, L., Decruvenaere, J.M. 2010. Quality of life after intensive care: a systematic review of the literature. Crit. Care Med. 38(12):23862499.

Orwelius, L., Nordlund, A., Edell-Gustafsson, U., Simonsson, P., Kristenson, M., Bendtsen, P., Sjöberg, F. 2005. Role of preexisting disease in patients’ perception of health-related quality of life after intensive care. Crit. Care Med. 33, 1557-1564.

Pattison, N., O’Gara, G., Wigmore, T. 2015. Negotiating transitions: involvement of critical care outreach teams in end-of-life decision making. Am. J. Crit. Care. 24(3),232-240.

Patton, M.Q. 2002. Qualitative research \& evaluation methods, SAGE Publications Inc., London. 
Peskett, M., Gibb, P. 2009. Developing and setting up a patient and relatives intensive care support group. Nurs. Crit. Care. 14(1), 4-10.

Polit, D.F., Beck, C.T. 2008. Nursing research. Generating and assessing evidence for nursing practice, eight ed. Lippincott Williams \& Wilkins, New York.

Ullman, A.J., Aitken, L.M., Rattray, J., Kenardy, J., Le Brocque, R., MacGillivray, S., Hull, A.M. 2015. Intensive care diaries to promote recovery for patients and families after critical illness: a Cochrane Systematic Review. Int. J. Nurs. Stud. 52(7), 1243 -1253.

Wade, D.M., Brewin, C.R., Howell, D.C., White, E., Mythen, M.G, Weinman, J.A. 2015. Intrusive memories of hallucinations and delusions in traumatized intensive care patients: An interview study. Br. J. Health Psychol. 20(3), 613-631.

Wåhlin, I., Ek, A.C., Idvall, E. 2009. 'Empowerment from the perspective of next of kin in intensive care‘, J. Clin. Nurs. 18(18), 2580-2587. 
Table 2. Summary of the subcategories and categories describing former intensive care patients' experiences of group meetings where they shared experience of critical illness with other former patients.

\begin{tabular}{|l|l|}
\hline Subcategories & Categories \\
\hline Getting insight & Meaningful discussions \\
\hline Confirmation & Understanding the meaning of surviving intensive \\
\hline Relief & care \\
\hline Going further & Giving and receiving strength \\
\hline & \\
\hline
\end{tabular}

